\title{
MODELOS DE FORMAÇÃO CONTINUADA DE PROFESSORES: transitando entre o tradicional e o inovador nos macrocampos das práticas formativas
}

\author{
TEACHER CONTINUOUS TRAINING MODELS: transiting between traditional and \\ innovative in macro fields of practice formation \\ MODELOS DE FORMACIÓN CONTÍNUA DEL PROFESSORADO: transitando en- \\ tre el tradicional y el inovador en los macrocampos de las prácticas formativas
}

\author{
Janaína da Silva Ferreira \\ Professora Mestre da Universidade do Estado do Rio de Janeiro (UERJ). \\ janainajoy2005@hotmail.com.br \\ José Henrique dos Santos \\ Professor Doutor da Universidade Federal Rural do Rio de Janeiro (UFRRJ). \\ henriquejoe@hotmail.com
}

\begin{abstract}
RESUMO: Este artigo visa refletir sobre a estrutura da formação continuada de professores, a partir da análise de diferentes concepções que regem e orientam suas práticas. A partir de uma revisão crítica da literatura, do tipo opinativa, percebe-se a existência de diferentes modelos estruturantes, influenciando sobremaneira o ensino, a aprendizagem e a formação dos professores. Estes modelos de formação se diferenciam em relação aos conceitos, objetivos e metodologias pelos quais são desenvolvidos a partir de distintos interesses e, por sua vez, moldam a natureza das aprendizagens docentes. Ao descrever tais perspectivas, busca-se relacioná-las com a realidade das práticas adotadas e desenvolvidas na atualidade pelos sistemas de ensino e nas escolas. O conhecimento destes modelos se mostra essencial para refletir sobre a associação das práticas de formação com as necessidades institucionais, dos professores e seu desenvolvimento profissional. Uma formação mais sintonizada com as necessidades dos professores será tanto mais efetiva considerando que, assim, mobilizará sua atenção e empenho em articular a teoria e a prática para a resolução de problemas relativos ao ensino e à aprendizagem, refletindo na melhoria da qualidade do processo educativo e, consequentemente, de todo o sistema educacional.
\end{abstract}

PALAVRAS-CHAVE: Formação de professores. Formação continuada. Modelos de formação.

ABSTRACT: This article aims to understand the structure of continuing education teachers, from the analysis of different concepts that govern and guide the practices in this area. Through a Critical Review of the Literature, opinionated type, we see the existence of different structural models, greatly influencing the teaching, learning and teacher training. The models differ in relation to the concepts, objectives and methodologies which are developed from different interests and, in turn, shape the nature of teaching learning. With the description of these perspectives, we seek to relate them to the reality of the practices adopted and developed by education systems and schools. Knowledge of these models becomes essential to reflect on the association of training practices to the needs of institutions, teachers and professional development. Training proposals guided by the teachers' needs will be more effective because their attention and efforts will turn to articulate the theory and practice to solve teaching and learning problems, reflecting the improvement of the quality of the educational process and, consequently, of all the educational system.

KEYWORDS: Teacher training. Continuing education. Training models.

Artigo recebido em setembro de 2016

Aprovado em novembro de 2016 
RESUMEN: Este artículo tiene como objetivo comprender la estructura de la educación continua de los maestros, a partir del análisis de los diferentes conceptos que rigen y guían las prácticas en esta área. A partir de una revisión crítica de la literatura, de tipo opinativa, se percebe la existencia de diferentes modelos estructurantes, que influyen en gran medida la enseñanza, el aprendizaje y la formación de lo profesorado.Los modelos difieren en relación a los conceptos, objetivos y metodologías que se desarrollan a partir de diferentes intereses y, a su vez, dan forma a la naturaleza de enseñanza y aprendizaje. Con la descripción de estas perspectivas, se busca relacionarlos con la realidad de las prácticas adoptadas y desarrolladas por los sistemas educativos y las escuelas. El conocimiento de estos modelos se convierte en esencial para reflexionar sobre la asociación de las prácticas de formación a las necesidades de las instituciones, los maestros y el desarrollo profesional. Propuestas de formación guiadas por las necesidades de los profesores serán más eficaces porque su atención y esfuerzos se vá a concentrar en articular la teoría y la práctica con vista en la resolución los problemas de enseñanza y aprendizaje, lo que refleja la mejora de la calidad del proceso educativo y de el sistema educativo.

PALABRAS CLAVE: Formación profesional. Educación continua. Modelos de formación. 
MODELOS DE FORMAÇÃO CONTINUADA | Janaína da Silva Ferreira e José Henrique

\section{1| INTRODUÇÃO}

Ao se abordar a formação profissional podemos analisá-la sob duas diferentes perspectivas: o formal, estruturado institucionalmente por organizações especializadas; e o informal, baseado na troca de conhecimentos entre os pares advindos da experiência prática e da interiorização de diferentes saberes (DEMAILLY, 1992).

$\mathrm{Na}$ prática profissional, estes conhecimentos se integram de forma dialética ou são constantemente confrontados revelando diferentes inquietações, anseios e necessidade de busca por atualização e contribuições que auxiliem o profissional em seu trabalho. A formação continuada é o tipo de formação em que o sujeito tem a possibilidade de obter novos conhecimentos, analisar e refletir sobre sua prática profissional. É o momento no qual se podem construir e ressignificar conhecimentos, crenças, valores e atitudes sobre a profissão.

$\mathrm{Na}$ profissão docente, caracterizada por exigir do professor habilidades específicas para lidar com o contexto tão heterogêneo que é a escola, a formação continuada torna-se mecanismo fundamental na busca por uma docência contextualizada e eficaz.

A literatura caracteriza três tipos de necessidades que a formação continuada deve atender: as necessidades pessoais, as profissionais e as organizacionais. A primeira vai ao encontro da necessidade pessoal de desenvolvimento profissional e da aquisição de novos conhecimentos que elevem o grau de competência e de sabedoria. A segunda visa atender as demandas profissionais, individuais ou de grupos, enquanto a terceira, relativa ao ambiente organizacional, se orienta para as demandas institucionais e para além do contexto escolar, focando nas demandas da sociedade em geral (PACHECO; FLORES; 1999).

Nesse sentido, a formação continuada deve ser regida pela associação entre necessidades individuais (professores), profissionais (demandas da profissão) e organizacionais (sistema educacional). Portanto, infere-se que um programa de formação continuada deve possuir como elemento central a colaboração entre os principais interessados no processo, tornando-se uma prática em que a troca de saberes, necessidades, interesses e experiências práticas sejam elementos fulcrais para as ações de "investigação-ação-formação".

No Brasil as orientações para a formação de professores do Ministério da Educação (BRASIL, 2006b) partem do princípio de que a formação continuada deve atender tanto às necessidades do sistema de ensino quanto às demandas dos professores em exercício. Porém, sabe-se que projetos desta natureza, por exemplo a formação entre pares, são ainda muito escassos, pois a individualidade que impera na prática docente dificulta qualquer ação de cunho colaborativo (FERREIRA; HENRIQUE; COSTA, 2015).

A formação continuada tem se feito presente nas principais reformas políticas no âmbito da formação de professores no Brasil. Principalmente após a década de 90, em que a sociedade passou por diferentes transformações econômicas, tecnológicas e sociais, este tipo de formação ttem se colocado como principal estratégia para a adequação do professor a este novo contexto (MACEDO, 2008). Nos últimos anos as políticas de formação têm sido instituídas no País com o foco na qualificação dos professores para atuarem em um contexto de trabalho diferente de vinte anos atrás e que demanda a cada dia o uso de novas metodologias de ensino que se adaptem à realidade social, econômica e tecnológica dos alunos (FERREIRA, 2012), assim, intensificando as políticas públicas no contexto da formação continuada de professores. Os órgãos nacionais de gestão educacional, com o objetivo de qualificar os professores do ensino básico, passam a estabelecer políticas de incentivo à formação inicial e continuada.

O Ministério da Educação (MEC), o Conselho Nacional de Educação (CNE) e a Secretaria de Educação Básica (SEB) implementaram, a partir da última década, diversas leis, decretos e pro- 
gramas de incentivo a formação continuada.

A Lei de Diretrizes e Bases da Educação Nacional (LDBEN) n 9.394/96- (BRASIL, 1996) estabelece no inciso II, art. 67 "que os sistemas de ensino deverão promover aperfeiçoamento profissional continuado, inclusive com licenciamento periódico remunerado para esse fim".

A Resolução n 03/97 (BRASIL, 1997), Artigo 5, do Conselho Nacional de Educação determina que os sistemas de ensino "envidarão esforços para implementar programas de desenvolvimento profissional dos docentes em exercício, incluída a formação em nível superior em instituições credenciadas, bem como, em programas de aperfeiçoamento em serviço".

Os referenciais para a formação de professores (BRASIL, 2002a), elaborados pelo MEC, orientam que a formação continuada deve considerar tanto as necessidades dos professores quanto dos sistemas de ensino.

Outra grande iniciativa desenvolvida pelo MEC é a Rede Nacional de Formação Continuada de Professores de Educação Básica (BRASIL, 2006b). Desenvolvido a partir do II Seminário da Rede Nacional de Formação Continuada de professores da Educação Básica, este documento estimula a articulação de centros de pesquisa e centros de educação pública para, em parceria com as universidades, produzirem materiais de apoio para os cursos à distância e semipresenciais, passando a atuar em rede para atender as demandas dos sistemas de ensino.

Já no início da década passada, o Plano Nacional de Educação (PNE) - Lei n 10.172/2001 (BRASIL, 2001), ao estabelecer os objetivos e metas para a formação inicial e continuada dos professores e demais servidores da educação, determinava ser necessário não só valorizar o magistério, como também estabelecer diretrizes de uma política globalizada neste campo que integrasse formação inicial, condições de trabalho, salário, carreira e a formação continuada. Enfatizava, ainda, a criação de programas articulados entre as instituições públicas de ensino superior e as secretarias de educação, de modo a elevar a qualidade do ensino.

Nesse sentido, o projeto de reforma universitária, apresentado pela Associação Nacional dos Dirigentes das Instituições Federais de Ensino Superior (ANDIFES, 2004), definiu que a educação superior tem como função, além de outras metas, proporcionar programas de formação continuada aos candidatos que atendam aos requisitos estabelecidos pelas instituições de ensino superior, incentivando a valorização profissional dos docentes.

O Plano Nacional de Educação (PNE) - Lei n 13.005/2014 (BRASIL, 2014) vigente enfatiza em sua décima sexta meta a garantia de oferta de formação continuada aos professores da educação básica em suas respectivas áreas, de acordo com as necessidades do contexto de ensino e das instituições que o administram. Como estratégias, orienta que a formação continuada seja planejada em regime de colaboração e ofertada por instituições públicas de ensino superior, de forma articulada às políticas de formação dos Estados, Distrito Federal e Municípios. Esta articulação torna-se mais evidente a partir do Decreto $n^{\circ}$ 6.094/2007 (BRASIL, 2007), que estabelece o Plano de Metas Compromisso Todos pela Educação. Estas metas influenciaram diretamente nas ações dos sistemas educacionais de estados e municípios brasileiros. A partir da adesão ao plano de metas, aos Estados e Municípios cabe diagnosticarem a situação educacional de suas instâncias, e a partir do Plano de Ações Articuladas (PAR) estabelecerem metas e estratégias que, em conjunto com o Ministério da Educação deverão ser concretizadas, visando à qualidade dos sistemas de ensino. Nestes projetos, a formação dos professores torna-se elemento fundamental para a melhoria da qualidade educacional, afetando não só as políticas para educação básica como também as políticas no campo da formação superior. Um dos projetos de valorização da formação do professor resultante da articulação entre os governos Federal, Estadual e Municipal com as Instituições de ensino superior é a implementação da Política Nacional de Formação de Professores da Educação Básica (PARFOR), instituída a partir do Decreto n 6.755/2009 (BRASIL, 2009), 
sendo revogada a partir de 2016 pelo Decreto $n^{\circ}$ 8.752/2016 (BRASIL, 2016), destacando em seus princípios a garantia de um padrão de qualidade aos cursos de formação inicial e continuada, entendidos como componentes essenciais à profissionalização.

Diante destas bases legais, nos últimos anos depreende-se a importância atribuída à formação continuada dos professores. O incentivo presente em leis e projetos incita a importância de se pensar este tipo de formação como elemento fundamental de suporte ao desenvolvimento profissional dos docentes.

Todavia, na atualidade, constatam-se duas perspectivas distintas de formação continuada: a clássica, caracterizada por um ensino diretivo regido pela lógica da racionalidade técnica, i.e, pela transferência de conhecimentos produzidos principalmente nas universidades e sem a preocupação com a experiência vivida pelos professores em seu ambiente de trabalho, a escola (COSTA, 2004); e a perspectiva interativo-reflexiva, comprometida com o desenvolvimento de uma formação que proporcione ao professor a reflexão constante sobre sua prática, a resolução dos problemas a partir de um processo colaborativo que incida na troca de saberes entre os docentes, e que contribua para a transformação da escola em lugar como locus central de formação continuada (BERNARDO, 2014).

No cenário atual predominam as formações de caráter clássico, realizadas mediante oferta de modalidades tradicionais (cursos, oficinas, palestras, etc.) que frequentemente visam atender aos interesses e necessidades do sistema educativo (FERREIRA, 2012; FERREIRA; HENRIQUE; COSTA, 2015). A introdução de modelos de formação inovadores tem esbarrado em contingências comuns aos sistemas de ensino e às escolas, como por exemplo, a ausência de políticas formativas sistemáticas, intencionais, articuladas e contínuas, bem como uma estrutura organizacional escolar que restringe as inovações e a adoção de perspectivas cooperativas de desenvolvimento profissional, respectivamente.

Neste cenário torna-se imprescindível refletir sobre a adoção de políticas comprometidas com uma formação continuada que possibilite ao professor o desenvolvimento de novas competências profissionais para atuar em um novo contexto escolar, com autonomia para construir novos conhecimentos e refletir sobre sua prática (PORTO, 2000).

O objetivo deste texto é apresentar e discutir, em diálogo com a literatura, os modelos de formação continuada presentes em diferentes referenciais que permeiam os estudos e as práticas nesta área. Para a realização deste estudo recorreu-se ao método de Revisão Crítica da Literatura, também caracterizado por Mancini e Sampaio (2006) como revisão opinativa, em que o pesquisador analisa evidências sobre um determinado tema ou assunto. Neste tipo de revisão não se recorre necessariamente a procedimentos padronizados de busca bibliográfica, mas não prescinde de resumir, analisar e sintetizar informações relativas ao problema investigado.

Nesse sentido, a revisão crítica se circunscreveu ao recenseamento de estudos na área de formação continuada, buscando se reportar às diferentes concepções e objetivos que estruturam a formação de professores, influenciando sobremaneira o ensino, a aprendizagem e a docência. Ao descrever tais perspectivas, busca-se relacioná-las com a realidade das práticas adotadas e desenvolvidas na atualidade pelos sistemas de ensino e nas escolas.

\section{2 | MODULAÇÃO DE APRENDIZAGENS NA FORMAÇÃO CONTINUADA}

Antes de analisar a formação continuada dos professores e seus diferentes modelos é importante analisar não só suas perspectivas de ensino intrínsecas, mas também como se modulam as diferentes formas de aprendizagem nestes processos.

Os modelos de formação podem ser analisados como projetos de formação inseridos dentro de 
uma perspectiva de ensino e que são sistematizados de acordo com o tipo de aprendizagem a que os professores são estimulados a desenvolver, seja uma construção de aprendizagem e de saberes pessoais ou voltados para o aprimoramento de técnicas e conhecimentos necessários ao desenvolvimento do sistema no qual está inserido.

Sabendo que o processo de formação envolve não só questões sobre o ensino, mas também o tipo de aprendizagem que se quer desenvolver, García (2002), a partir de um modelo caracterizado por Chang e Simpson (1997), descreve quatro modelos de aprendizagem existentes na formação continuada.

O primeiro é estruturado por meio de Cursos que compreendem o aprender de outros. Baseia-se na aplicação de conteúdos elaborados por especialistas em algum campo do conhecimento disciplinar. Embora os cursos sejam realizados em reuniões grupais, a aprendizagem é sempre individual.

Os Seminários e grupos induzem ao aprender com os outros, e são processos formativos de aprendizagem grupal, com fins colaborativos. Este tipo de aprendizagem não precisa necessariamente ser presencial, pois este processo baseia-se na realização de metas e de objetivos de aprendizagem comuns ao grupo.

O terceiro modelo possui como característica a Autoformação representando o aprender sozinho. Considera que os processos de aprendizagem podem ser administrados por qualquer profissional. A autoformação é aberta, possibilitando ao profissional determinar suas próprias metas de aprendizagem de acordo com sua experiência de vida profissional. Une a experiência vivida e a reflexão constante sobre a prática. É importante, neste tipo de formação, considerar a experiência dos professores como fator essencial no processo de desenvolvimento da reflexão e da aprendizagem.

O quarto modelo é a Aprendizagem informal, desenvolvida por meio de informações ocasionais e de experiências entre pares. É considerado um modelo de formação aberto e informal, mas não deixa de ser um tipo de aprendizagem importante para o desenvolvimento profissional.

As duas primeiras formas de aprendizagem apresentadas possuem como característica comum serem cursos de formação fechados, com disciplinas específicas e bibliografias determinadas pelo formador (FERRO, 2008). Já as duas últimas são caracterizadas pela forma livre e autônoma de aprendizagem.

Como mecanismo auxiliar de formação, Garcia ainda apresenta o termo Teleformação para designar os recursos tecnológicos desenvolvidos para suprir alguns empecilhos da formação continuada. Esta modalidade caracteriza-se como uma formação a que se recorre, por exemplo, para uma formação de caráter distancial, semi-presencial ou presencial, com necessidade de contatos reais entre formadores e formandos ou à distância mediante videoconferências. Sustenta-se nas diversas ferramentas tecnológicas, de telecomunicação, materiais multimídia, etc, denominadas TICs. A internet e suas possibilidades viáveis de conhecimento são utilizadas como principal mecanismo de acesso às infomações.

A teleformação, em particular, é uma ferramenta bastante utilizada na atualidade nos programas de formação de professores. A tendência ao uso tecnológico na Educação inicia-se com o advento da internet e a partir daí surgem algumas modalidades auxiliares do processo de ensino-aprendizagem.

Em relação às TICs considera-se que estas ferramentas vêm sendo muito utilizadas como mecanismos de aprendizagem na atualidade. A criação de diversas plataformas de educação à distância por meio destas tecnologias engloba um conjunto de ações promovidas pelo governo para incentivar a formação inicial e continuada dos professores. A Universidade Aberta do Brasil (BRASIL, 2006a) criada pelo Ministério da Educação em parceria com os Estados, Municípios e Universidades Públicas é um exemplo do uso das ferramentas tecnológicas para promoção e desenvolvimento da formação inicial e continuada à distância para os profissionais do magistério. 
Os modelos de aprendizagem retratam diversas possibilidades de internalização do conhecimento. No que diz respeito à formação continuada estas aprendizagens se manifestam a partir dos objetivos e finalidades a que se pretende alcançar. A caracterização da aprendizagem possui relação direta com o tipo de conhecimento que se deseja alcançar, i.e, com as diferentes concepções acerca da função deste tipo de formação para o desenvolvimento profissional.

\section{3 | MODELOS DE FORMAÇÃO CONTINUADA: Concepções, socialização e necessidades na formação continuada}

Ao se refletir sobre a formação continuada dos professores, torna-se necessário entender as dife- rentes concepções existentes neste campo e todo o contexto que envolve sua prática. As teorias que fundamentam as ações de formação continuada delimitam diferentes modelos (GARCÍA, 2002). Os modelos de formação surgem mediante intenções e finalidades e se concretizam com base em correntes paradigmáticas que suportam teoricamente os projetos de formação.

Entende-se o termo modelo como um conjunto de relações de poder, culturas, crenças e valores estabelecidos entre as instituições/redes/sistemas de ensino com os sujeitos envolvidos no processo formativo (formadores e formandos), tendo como características implícitas objetivos particulares e maneiras de conduzir as práticas formativas. As ações são regidas por uma lógica particular de pensar, organizar e agir sobre a prática.

Não é intuito, neste texto, conceber os modelos de formação com organização e estrutura individuais e dissociáveis, mas sim assinalar particularidades inerentes às práticas de formação dos professores. Os modelos apresentados devem ser depreendidos a partir de seus referenciais teóricos associados aos objetivos e interesses de indivíduos e sistemas educativos sem necessariamente se sobreporem, já que transportam intenções implícitas ou explícitas além de depender das motivações e condições dos entes envolvidos. Propõe-se analisar a natureza inerente, assim como os objetivos, necessidades e formas de organização implícitos nos modelos de formação continuada, relacionando-os com as práticas atuais de formação.

Há décadas as publicações científicas identificam diferentes finalidades e objetivos na formação continuada de professores, inclusive, no Brasil, relacionando-os a diferentes momentos históricos e seus determinantes políticos, econômicos e sociais (FERREIRA; HENRIQUE; COSTA, 2015). Assim, identificou-se a predominância da concepção tradicional entre as décadas de 1950/70, em que predominou uma vertente eminentemente reprodutora voltada à transmissão de conteúdos e à mudança de atitudes dos professores; do movimento escolanovista, que na década de 1960 ressaltava uma formação comprometida com o domínio de métodos e técnicas de ensino-aprendizagem, mas que colocavam o professor em segundo plano e muitas vezes incorria em práticas espontaneístas, quando não tradicionais; da tendência tecnicista a partir da década de 1970, acompanhando o crescente processo de industrialização nacional; da tendência crítico-reprodutivista a avultar a necessidade de compreender a interdependência entre educação e a sociedade capitalista; da perspectiva crítico-superadora, que por volta dos anos 1980 enfatizava o espaço escolar como locus de transformações sociais; e, a mais recente, a perspectiva contemporânea, que se baseia na formação crítica, reflexiva, valorizadora do saber e das necessidades dos professores contextualizadas às demandas do trabalho escolar (FUSARI, 1988; ALTENFELDER, 2005; MOREIRA, 2006; PAIM; LORO; TONETTO, 2008).

Portanto, o intuito destas análises foi compreender os objetivos e aplicação dos modelos/projetos/concepções de formação consoante às pretensas consequências para os sistemas escolares e para o processo de desenvolvimento profissional docente. . 
Em 1987, Eraut caracterizou quatro paradigmas dominantes na formação continuada, nomeadamente, da Deficiência, do Crescimento, da Mudança e a Solução de Problemas. O Paradigma da Deficiência sustenta-se na ideia de que os professores necessitam de atualização para a construção de saberes e competências não desenvolvidos na formação inicial, porém necessários à prática docente e a sua devida ambientação ao contexto em que atua. A formação é desenvolvida a partir das necessidades identificadas pelo sistema e/ou administração escolar. Assim, este tipo de formação passa a ser administrada pelos órgãos superiores, ficando o professor a elas subordinado.

O Paradigma do Crescimento está relacionado com a busca pelo desenvolvimento profissional. Os professores no decorrer de sua experiência profissional reconhecem suas necessidades e deficiências, sendo eles mesmos responsáveis por gerir sua formação.

O Paradigma da Mudança coloca a formação como um processo de colaboração e negociação entre os sujeitos interessados em reorganizar e reorientar saberes e competências em função das demandas decorrentes do contexto de ensino. Esta negociação tem o objetivo de desenvolver no professor novos saberes e novas competências profissionais de acordo com as necessidades diagnosticadas a priori.

O quarto paradigma, Solução de Problemas, orienta a formação do professor para a resolução dos problemas da escola identificados e analisados pelos próprios professores. O objetivo é que os professores adquiram competências para a resolução dos problemas relativos à sua prática e seu contexto de atuação profissional.

Quanto ao processo de desenvolvimento das ações formativas, Ferry (1987) apresenta três diferentes modelos existentes na formação dos professores, caracterizados principalmente, a partir do processo de socialização entre os sujeitos envolvidos na formação, assim, centrado nas aquisições, no processo e na situação.

No modelo centrado nas aquisições, a formação tem a função de desenvolver e aperfeiçoar conhecimentos e com isso aumentar o nível de competência profissional dos professores. A formação acontece de maneira direta e objetiva, preocupando-se apenas em cumprir as metas antes estabelecidas. Destaca-se a subordinação da prática relacionada à teoria, em que os conteúdos são determinados por quem é o responsável pela formação, ficando o professor e sua prática afastados na concepção destes conteúdos.

O modelo centrado no processo considera importante toda a experiência vivida pelo professor no processo de formação. O professor é o responsável pela sua formação, tendo autonomia para gerir seu processo de aprendizagem.

O terceiro é o modelo centrado na situação, que parte do princípio de que a formação deve proporcionar a reflexão e análise da prática. O professor ao analisar e refletir sobre os problemas vivenciados na sua prática cria e desenvolve possibilidades de mudança, tentando torná-la mais significativa. A principal estratégia de formação é tornar o professor um investigador de sua própria prática.

Percebe-se, nestas caracterizações, diferentes concepções e interesses implícitos no processo de formação continuada, a saber, o pessoal, o da prática profissional e os institucionais. A ênfase conferida a determinada necessidade em específico acaba por diferenciar os objetivos e as práticas formativas.

Pacheco e Flores (1999) analisam a formação continuada sob três diferentes tipos de necessidades. Quando elaborada sob uma perspectiva administrativa, por exemplo, as ações de formação enfatizam as necessidades organizacionais. São desenvolvidas por instâncias superiores (redes/sistemas/instituições) que utilizam normalmente como estratégias modalidades expositivas e de curta duração (palestras, capacitação, etc.) visando modificações estruturais, operacionais ou pedagógicas nas escolas de uma rede de ensino. Observa-se a maior preocupação com o funcionamento do sistema educativo, sem levar em conta as necessidades formativas dos profes 
sores, até mesmo para operar as mudanças pretendidas.

$\mathrm{Na}$ perspectiva individual o professor é o elemento central de sua formação, buscando mecanismos de autoformação, em que ele mesmo procura conhecimentos, a qual também pode se concretizar por meio da heteroformação, quando estabelecida por um grupo de professores, tendo um mediador como dinamizador do processo de formação.

Já a perspectiva de colaboração socialintegra os interesses institucionais e individuais. A formação é orientada para a articulação entre o saber teórico e o saber advindo da prática. Os professores são colocados no papel de principais responsáveis por seu processo formativo. É característica deste modelo a colaboração das instituições superiores na organização e na escolha metodológica da formação na escola, entendido como principal locus de formação (PACHECO; FLORES, 1999).

A partir destas análises é possível identificar algumas semelhanças e diferenças entre os modelos apresentados. Respeitado o modo de sistematização dos autores referenciados, constata-se um consenso em compreender as intenções implícitas na estrutura e organização da formação continuada, em que os diferentes interesses e necessidades subsidiarão a oferta e a demanda por cada tipo de formação. Também, os modelos e perspectivas apresentados discriminam a centralidade da formação, seja institucional, pessoal (na figura do professor), ou na escola como espaço problematizador, como tal, dependendo de formação e ação integradas e contextualizadas pelos agentes educativos.

Em todos os casos, o professor se coloca como principal agente de mudança. Ao entendê-lo como protagonista da formação, percebe-se nestes modelos processos distintos de socialização e participação do professor, em consonância com os diferentes objetivos implícitos (Quadro 1).

$$
\begin{aligned}
& \text { Quadro } 1 \text { - Caracterização do papel do professor nos diferentes modelos } \\
& \text { de formação continuada }
\end{aligned}
$$

\begin{tabular}{|c|c|c|}
\hline Paradigmas/ Concepções & Características/ Natureza da formação & $\begin{array}{c}\text { Finalidade - Socialização } \\
\text { do professor }\end{array}$ \\
\hline Deficiência & Institucionalizada; & \multirow{3}{*}{ Objeto da formação } \\
\hline Aquisições & Administrativa; & \\
\hline Administrativa & Organizacional. & \\
\hline Crescimento e Mudança & Compensatória; & \multirow{3}{*}{ Agente da formação } \\
\hline Processual & Individualizante; & \\
\hline Individual & Baseado em competências pessoais. & \\
\hline Solução de problemas & Centrada na escola; & \multirow{3}{*}{ Observador de situações } \\
\hline Situacional & Valoriza o saber/experiência docente; & \\
\hline Colaboração social & Cooperativa/ Colaborativa. & \\
\hline
\end{tabular}

Fonte: formulada pelos autores com base em Eraut (1987), Ferry (1987), Pacheco e Flores (1999).

Contextualizando estas análises na atualidade, ainda identifica-se a ênfase em propostas de formação focadas em interesses exteriores aos anseios do professor. No que diz respeito às normas estabelecidas nas políticas públicas definidas no Brasil, é nítido o incentivo à formação continuada como um mecanismo de crescimento profissional e pessoal. Os PCNs (BRASIL, 2002b) e as Orientações da Rede Nacional de Formação Continuada de Professores (BRASIL, 2006b) consideram que a formação continuada deve partir da motivação pessoal do professor na busca pelo seu desenvolvimento profissional, e que aos sistemas de ensino cabe a responsabilidade de desenvolver ações de incentivo à qualificação docente. Porém, as práticas de formação con 
tinuada na atualidade, majoritariamente, ainda tem se estabelecido consoante necessidades decaráter burocrático e administrativo, descentrando seus objetivos dos anseios e da prática do professor, denunciando a concentração nos objetivos e necessidades institucionais.

Quanto à colaboração, na atualidade ainda são incipientes propostas desta natureza. Embora os professores valorizem esta prática como significativa ao seu desenvolvimento profissional (FERREIRA; HENRIQUE; COSTA, 2015; BERNARDO, 2014), a escola tem destinado pouco ou nenhum tempo à reflexão, discussão e análise do contexto e das práticas educativas desta natureza.

\section{4| ORGANIZAÇÃO E ESTRUTURA DA FORMAÇÃO CONTINUADA}

Demailly (1992), se valendo do princípio relativo à organização e estrutura da formação continuada, descreve quatro modelos existentes na prática de ensino e formação: universitário, escolar, contratual e interativo-reflexivo. Estes modelos estão estruturados sob diferentes aspectos conceituais e relacionais entre a instituição responsável, os agentes formadores e aqueles que receberão a formação.

O modelo universitário caracteriza-se pela relação recíproca entre formador e formando, em que as competências pessoais e profissionais do formador são consideradas importantes para o formando. Nesta relação o formador é visto como um mestre, tendo como responsabilidade a transmissão de seus conhecimentos teóricos e de seu saber já constituído. A principal característica existente nessa relação é o caráter voluntário do formando, ao participar do processo de formação motivado pelas referências conceituais e experienciais do formador, estabelecendo uma relação mútua entre discípulo e mestre, em que o segundo seja capaz de produzir conhecimentos mediante investigação conjunta e não apenas por simples transferência. Este tipo de formação pode ser encontrado em alguns cursos de pós-graduação latu sensu e strito sensu, entre outros.

No modelo escolar as formações são organizadas e estruturadas por instâncias de poder exteriores aos docentes e a própria escola - Igreja, Estado ou Nação (DEMAILLY, 1992). Os objetivos e interesses são de caráter superior, i.e., interesses institucionais em que o formador apenas propaga conhecimentos que se constituem a partir de conteúdos determinados a priori pela instituição responsável pelo programa de formação. A formação realizada vai quase sempre ao encontro dos objetivos da instituição, que procura legitimar e redefinir seus projetos e intenções. A instituição pode ser estatal ou não, pois o poder pode ser delegado às instituições privadas, que assumem o papel das instituições responsáveis seguindo suas determinações.

A obrigatoriedade, tanto para os formandos quanto para os formadores, que juntos são incumbidos de compartilhar o processo de formação, e o caráter legítimo de relação institucional, são características inerentes a este modelo. Esta obrigatoriedade faz com que se estabeleçam relações coercivas e constrangedoras na prática pedagógica, ocasionando diversos questionamentos sobre este modelo quando comparado a outros. Ressalta-se a característica tradicional e clássica presente neste modelo denotando uma maior organização, na atualidade, de práticas com ênfase em atender as necessidades institucionais.

A formação continuada tem se concretizado atualmente em ações de interesse exclusivo do sistema. Muitos professores relatam que os planejamentos institucionais não atendem satisfatoriamente às suas necessidades (CRISTINO; KRUG, 2008). Esta condição contribui para ratificar a formação continuada como uma prática de caráter clássico, que acontece de maneira técnica, comercial e desvinculada da realidade educacional (MOLINA NETO, 1997) sendo baseada apenas na transmissão de conhecimentos, ao passo que desvaloriza as experiências vividas na prática pelos professores e a reflexão sobre a mesma. Vale ressaltar que as críticas ao modelo clássico não subestimam sua eficiência, mas expõem, em parte, sua ineficácia ao atendimento das 
necessidades dos professores. A principal crítica é a de que este modelo pode ser eficiente para atender às demandas e necessidades do sistema, porém, suas ações características vão primariamente ao encontro de necessidades e interesses exteriores ao professor e a sua prática, concretizando-se muitas vezes em programas de transmissão e aplicação de conteúdos que acabam se desvinculando da prática reflexiva e contextualizada.

O modelo contratual é caracterizado pela relação estabelecida entre formador e formando mediante contrato entre ambos ou mediado por outras parcerias. A formação pode ser negociada entre dois ou mais responsáveis por este processo. São estabelecidas relações contratuais entre diferentes instâncias. Esses contratos podem ser acordados entre a instituição responsável pelo formador e a estrutura que pretende contratá-lo; a estrutura e a empresa cliente; a empresa cliente com o formando (contratado pela empresa e enviado para o programa de formação). Os contratos são formalizados mediante diferentes parcerias, concretizando-se em distintas modalidades de formação desenvolvidas conforme negociação realizada entre os parceiros.

O modelo interativo-reflexivo pode ser compreendido como a formação que acontece entre os pares e por aprendizagem mútua entre os formandos. Procura-se por meio da formação a resolução de problemas comuns ao cotidiano de trabalho. A formação no espaço escolar se constitui a partir de decisões construídas e desenvolvidas coletivamente no intuito de resolver problemas ligados não só a prática, mas também do contexto escolar em geral. A reflexão, a construção e a troca de saberes são suas características principais. O formador, quando externo ao grupo, funciona como um mediador no processo de reflexão e resolução dos problemas. $O$ ambiente escolar é o principal espaço para a realização deste tipo de formação, pois a escola, através da interação entre professores e alunos, é o espaço onde acontece a construção dos saberes e que torna a prática mais significativa na formação social e intelectual tanto dos alunos quanto dos professores (COLLARES; MOYSÉS; GERALDI, 1999). É sob este modelo que se conceituam as inovadoras práticas de formação continuada, as quais antagonizam com a prática tradicional - pois esta carece de base para tornar a prática de formação continuada eficaz e significativa, a partir das quais se constroem novas perspectivas formativas integradoras das necessidades coletivas de professores e do contexto escolar em que atuam.

O reconhecimento da prática crítico-reflexiva é também percebido e valorizado pelos professores, ao identificarem que os estudos, seminários e reflexões coletivas os ajudam a enxergar uma nova realidade antes não vivida (CALDEIRA, 2001). Analisam esta prática como um processo colaborativo de trocas de saberes e experiências, na busca por resolução dos problemas oriundos de um contexto comum aos professores e comunidade escolar (BERNARDO, 2014). Embora recentes pesquisas mostrem a importância da formação crítico-reflexiva, sua prática ainda é pouco difundida, pois alguns empecilhos dificultam a relação entre professores, bem como a formação centrada na escola. A dificuldade em reunir um grupo de professores para desfrutar deste tipo de formação tem tornado o modelo pouco exequível nas escolas. A falta de incentivo dos sistemas de ensino e a extensa jornada de trabalho a que estão submetidos os professores são fatores que interferem significativamente na realização desta prática de formação.

A análise da organização e estruturação da formação continuada proposta por Demailly (1992) permite relacionar as estruturas dos modelos universitário e escolar com o paradigma de formação centrado no como "déficit" (ERAUT, 1987), pois tratam a formação continuada como um mecanismo capaz de suprir a lacunas deixadas pela formação inicial, e com o objetivo de atualização profissional dos professores. Sob a concepção de que a formação continuada deve suprir deficiências da formação inicial ou que a prática pedagógica está em constante mudança, exigindo ao professor novas competências, o paradigma do déficit coloca a formação continuada como um mecanismo de aprofundamento dos conhecimentos necessários à docência. Porém, embora 
objetive a construção de competências que auxiliem o professor a lidar com um contexto em constante transformação, sob esta abordagem o professor acaba se tornando mero objeto das ações de capacitação (FUNDAÇÃO CARLOS CHAGAS, 2011), tornando as práticas descontextualizadas do cotidiano laboral.

As características presentes nos modelos e estruturas analisados remetem a reflexão sobre a fundamentação crítica acerca dos distintos objetivos atribuídos à formação continuada, denotando o confronto de interesses e necessidades que lhes são inerentes.

As críticas aos modelos em que a formação continuada deve partir do interesse voluntário do professor em função de suas perspectivas profissionais e pessoais de desenvolvimento, ou ser desenvolvida por agentes que atuam no próprio ambiente educacional, partem do princípio de que bons projetos de formação continuada não podem ser elaborados pelos docentes ou pela escola, na medida em que estes estão tão imersos no contexto, tornando-se impossível se distanciarem de sua realidade para avaliar as reais necessidades, sistematizá-las e assim propor melhores mecanismos de execução (GUSKEY; HUBERMAN, 1995). Critica-se o fato de que uma formação somente centrada no professor e sua necessidade impede a construção de propostas superadoras no meio educacional, consideradas mais importantes que as questões pessoais docentes.

Por outro lado, na literatura o que tem imperado é justamente a crítica sobre as práticas de formação continuada que desconsideram as expectativas e anseios dos professores, pois acredita-se que os interesses, necessidades e a prática dos professores devem ser consideradas em quaisquer programas de formação. Tais críticas enfatizam a ideia de que a formação continuada deve se tornar contextualizada ao ambiente e cotidiano profissional dos professores, pois, caso contrário, corre-se o risco dos professores se sentirem desmotivados e desinteressados no processo de transformação educacional e a não investirem no processo formativo.

Os modelos de formação trazem consigo diferentes intenções e objetivos, sejam eles voltados para as necessidades dos professores ou para os sistemas/redes/instituições responsáveis pela Educação. A partir destas análises pode-se inferir que a formação continuada dos professores é idealizada e estruturada, de maneira a atender às necessidades tanto dos professores (embora em menor escala) quanto das instituições educacionais (escola, secretarias de educação e diferentes esferas governamentais). Sua eficácia e contribuição para o desenvolvimento profissional dos professores possui relação direta com as concepções atreladas às suas ações.

Ao analisar os estudos recentes sobre este tema (FUNDAÇÃO CARLOS CHAGAS, 2011; FERREIRA, 2012; BERNARDO, 2014) verifica-se o consenso de que a formação continuada atual deve ser capaz de desenvolver competências e reflexões a partir dos anseios dos próprios professores, advindos de seu contexto profissional, das exigências históricas, culturais e econômicas da sociedade. Ressalta-se o emprego utilitarista desta formação para suprir necessidades dos sistemas/redes/instituições e para a adequação do ensino às diferentes exigências políticas e econômicas. Porém, critica-se a predominância e a ênfase em modelos centrados no desenvolvimento e atendimento às demandas institucionais. Equilibrar estes diferentes objetivos, interesses e necessidades tem sido o grande desafio da formação continuada.

\section{5| CONSIDERAÇÕES FINAIS}

O propósito deste texto foi rememorar, analisar e refletir sobre a estrutura organizacional e os modelos de formação continuada. A evidência teórica da existência de distintas estruturas e modelos de formação permite depreender como se estabelecem as ações desta natureza e suas particularidades quanto à mobilização dos agentes envolvidos (Instituições, formadores e formandos), os 
mecanismos de aprendizagem e a repercussão destas práticas formativas para os atores educacionais, as instituições e os alunos, comprometidos com a qualidade da educação básica em nosso país.

A literatura reitera a premência da mudança do paradigma de formação clássico para o interativo-reflexivo, de modo a valorizar a experiência e as necessidades dos professores associadas às demandas da escola e dos alunos. No entanto, considerando que a complexidade da realidade escolar gera distintas necessidades de formação dos professores, é preciso aceitar a incompletude da ciência para prever os moldes de uma formação que dê conta da diversidade do contexto educacional. Se por um lado as ações de formação continuada no âmbito institucional dos sistemas de ensino convergem para o desenvolvimento da qualidade da educação básica e a transparência de suas ações à sociedade, por outro deve contemplar as necessidades de formação dos professores e ao seu desenvolvimento profissional, pois deles também dependem a eficácia do processo educativo. Nesse sentido, integrar as necessidades dos professores às necessidades institucionais parece, ainda, ser um grande desafio para as políticas de formação de professores.

De certo, face a sua responsabilidade social, os sistemas educacionais devem estabelecer diretrizes gerais e metas de eficiência para a sua atividade fim, cabendo-lhe adotar medidas no sentido de preparar os professores para o seu desenvolvimento e alcance. Entretanto, por outro lado, as escolas representam núcleos singulares e, como tal, requerem dos respectivos sistemas a adoção de políticas e processos de gestão que permitam autonomia aos gestores educacionais e professores no sentido de promoverem ações conjugadas e contextualizadas em sintonia com as diretrizes mais gerais e, no plano mais específico, com o projeto político escolar. O desenvolvimento de formações massivas, diretivas e normalizadoras para os professores, orientadas para o desenvolvimento de conhecimentos que permitam o alcance de metas mais gerais pelos sistemas de ensino não garante a sua imediata efetivação na sala de aula (GUSKEY, 2000).

Apesar da corrente conceitual que se manifesta na formação continuada levarem-na para uma prática reflexiva e crítica, e da constatação de que a formação tradicional não está sendo suficiente para a transformação da prática pedagógica, torna-se importante salientar em que medida estas práticas vão ao encontro das necessidades dos professores abrindo caminhos para uma nova organização e estrutura destas ações.

Reconhece-se que não é tarefa fácil conjugar perspectivas de formação que atendam aos interesses institucionais e docentes em simultâneo. Ainda assim, constitui um desafio considerar as necessidades de formação do professor face aos problemas com os quais ele se defronta durante o cumprimento de sua tarefa educativa. Uma formação mais sintonizada com as necessidades dos professores será tanto mais efetiva considerando que, assim, mobilizará sua atenção e empenho em articular a teoria e a prática para a resolução de problemas relativos ao ensino e à aprendizagem, refletindo na melhoria da qualidade do processo educativo, e consequentemente de todo o sistema educacional.

Refletir sobre estas estruturas e modelos que norteiam a formação continuada de professores nos permite contextualizá-los à realidade educacional, na tentativa de compreender como tem sido desenvolvidas as políticas neste campo. Entender as diferentes concepções e finalidades implícitas na organização da formação contribui para encaminhamentos políticos que subsidiem propostas que coadunem com as diferentes esferas do campo educacional, e que possibilitem não só a qualificação dos sistemas/redes/instituições, mas que principalmente tornem o ensino-aprendizagem efetivo e significativo aos professores e alunos. 


\section{Referências}

ALTENFELDER, A. H. Desafios e tendências em formação continuada. Construção Psicopedagógica, São Paulo, v. 13, n. 10, 2005. Disponível em: <http:// pepsic.bvsalud.org/scielo.php?script=sci_arttext\&pid=\$141569542005000100004\&lng=pt\&nrm=iso $>$. Acessos em: 26 abr. 2016.

ANDIFES. Reforma universitária: proposta da ANDIFES para a reestruturação da educação superior no Brasil. Brasília, DF: ANDIFES, 2004. Disponível em: <http://www.andifes.org.br/wp-content/files_flutter/1364828028PropostaAndifes.pdf >. Acesso em: 4 mar. 2016.

BERNARDO, F. B. Formação colaborativa em educação física: do isolamento docente a colaboração entre pares. 2014. 119f. Dissertação (Mestrado em Educação) - Universidade Federal Rural do Rio de Janeiro, Seropédica, RJ, 2014.

BRASIL. Decreto $n^{\circ} 5.800$, de 8 de junho de 2006. Dispõe sobre o sistema Universidade Aberta do Brasil UAB. Diário Oficial da União. Brasília, DF, 9 jun. 2006a.

. Decreto $n^{\circ} 6.094$, de 24 de abril de 2007. Dispõe sobre a implementação do plano de metas compromisso todos pela educação, pela União Federal, em regime de colaboração com Municípios, Distrito Federal e Estados, e a participação das famílias e da comunidade, mediante programas e ações de assistência técnica e financeira, visando a mobilização social pela melhoria da qualidade da educação básica. Diário Oficial da União. Brasília, DF, 25 abr. 2007.

. Decreto $n^{\circ} 6.755$, de 29 de janeiro de 2009. Institui a política nacional de formação de profissionais do magistério da educação básica, disciplina a atuação da Coordenação de Aperfeiçoamento de Pessoal de Nível Superior-CAPES no fomento a programas de formação inicial e continuada, e dá outras providências. Diário Oficial da União, Brasília, DF, 30 jan. 2009.

Decreto $n^{\circ} 8.752$, de 9 de maio de 2016. Dispõe sobre a política nacional de formação dos profissionais da educação básica. Diário Oficial da União. Brasília, DF, 10 maio 2016.

. Lei $n^{\circ} 9.394$, de 20 de dezembro de 1996. Estabelece as diretrizes e bases da educação nacional. Diário Oficial da União. Brasília, DF, 23 dez. 1996.

Lei $n^{\circ} 10.172$, de 9 de janeiro de 2001. Aprova o plano nacional de educação e dá outras providências. Diário Oficial da União. Brasília, DF, 10 jan. 2001.

Lei $n^{\circ} 13.005$, de 25 de junho de 2014. Aprova o Plano Nacional de Educação - PNE e dá outras providências. Diário Oficial da União. Brasília, DF, 26 jun. 2014.
Ministério da Educação. Secretaria de Educação Básica. Rede nacional de formação continuada de professores de educação básica. Brasília, DF: MEC; SEB, 2006b. 208 p. Disponível em: <http://portal.mec. gov.br/seb/arquivos/pdf/Rede/catalg_rede_06.pdf $>$. Acesso em: 24 jul. 2012.

Ministério da Educação. Secretaria de Educação Fundamental. Referenciais para formação de professores. Brasília, DF: MEC; SEF, 2002a. Disponível em: <http://www.mec.gov.br>. Acesso em: 24 jul. 2012.

Ministério da Educação. Secretaria de Educação Média e Tecnológica. PCN+ ensino médio: orientações educacionais complementares aos parâmetros curriculares nacionais: linguagens, códigos e suas tecnologias. Brasília, DF: MEC; SEMTEC, 2002b. Disponível em: <http://www.mec.gov.br>. Acesso em: 24 jul. 2012.

Resolução $n^{\circ} 3$, de 8 de outubro de 1997. Fixa diretrizes para os novos planos de carreira e de remuneração para o magistério dos Estados, do Distrito Federal e dos Municípios. Diário Oficial da União. Brasília, DF, 13 out. 1997.

CALDEIRA, A. M. S. A formação de professores de educação física: quais saberes e quais habilidades? Revista Brasileira de Ciências do Esporte, Campinas, v. 22, n. 3, p. 87-103, maio 2001. Disponível em: <http://revista.cbce. org.br/index.php/RBCE/issue/view/93>. Acesso em: 20 abr. 2012.

CHANG, E.; SIMPSON, D. The circle of learning: individual and group processes. Educational Policy Analysis Archives, v. 5, n. 7, p. 1-21, fev. 1997. Disponível em: $<$ http://epaa.asu.edu/ojs/article/view/608> . Acesso em: 20 jun. 2011.

COLLARES, C. A. L.; MOYSÉS, M. A. A.; GERALDI, J. W. Educação continuada: a política da descontinuidade. Educação e Sociedade, Campinas, ano 20, n. 68, p. 202219, dez. 1999. Disponível em: <http://www.scielo.br/pdf/ es/v20n68/a11v2068.pdf>. Acesso em: 20 abr. 2012.

COSTA, N. M. L. A formação contínua de professores: novas tendências e novos caminhos. Holos, Natal, ano 20, v. 3, p. 63-75, dez. 2004. Disponível em: <http://www2. ifrn.edu.br/ojs/index.php/HOLOS/article/view/48/52>. Acesso em: 20 abr. 2012.

CRISTINO, A.; KRUG, H. Um olhar crítico reflexivo sobre a formação continuada de professores de educação física da rede municipal de santa Maria. Movimento, Porto Alegre, v. 14, n. 1, p. 63-83, jan./abr. 2008. Disponível em: <http://www.seer.ufrgs.br/Movimento/article/viewFile/2129/2073>. Acesso em: 1 maio 2012. 
DEMAILLY, L. C. Modelos de formação continuada e estratégias de mudança. In: NÓVOA, A. (Org.). Os professores e a sua formação. 2. ed. Lisboa: Dom Quixote, 1992.

ERAUT, M. Inservice teacher education. In: DUKIEN, M. (Org.). The international encyclopedia of teaching and teacher education. Oxford: Pergamon, 1987. p. 730-747.

FERREIRA, J. S. Perfil da formação continuada e autoavaliação de competências docentes na educação física escolar. 2012. 104f. Dissertação (Mestrado em Educação)- Universidade Federal Rural do Rio de Janeiro, Seropédica, RJ, 2012.

FERREIRA, J. S.; HENRIQUE, J. S.; COSTA, B. O. Perfil de formação continuada de professores de educação física: modelos, modalidades e contributos para a prática pedagógica. Revista Brasileira de Ciências do Esporte, Campinas, v. 37, n. 3, p. 289-298, 2015. Disponível em: <http://www.rbceonline.org.br/>. Acesso em: 5 dez. 2015.

FERRO, F. A percepção de necessidades de formação em educação física e o desenvolvimento profissional dos professores: um estudo sobre a importância da formação contínua como fator do desenvolvimento profissional. 2008. 109f. Dissertação (Mestrado em Ciências da Motricidade) - Faculdade de Motricidade Humana, Universidade Técnica de Lisboa, Lisboa, Portugal, 2008.

FERRY, G. Le traject de la formation. Paris: Dunod, 1987.

FUNDAÇÃO CARLOS CHAGAS. Formação continuada de professores: uma análise das modalidades e das práticas em estados e municípios brasileiros. São Paulo: Fundação Victor Civita, 2011. 129 p. Relatório final do estudo realizado pela Fundação Carlos Chagas por encomenda da Fundação Victor Civita. Disponível em: $<$ http://www.fvc.org.br/pdf/relatorio-formacao-continuada.pdf>. Acesso em: 15 jun. 2011.

FUSARI, J. C. A educação do educador em serviço: treinamento de professores em questão. 1988. Dissertação (Mestrado em Filosofia da Educação) - Pontifícia Universidade Católica de São Paulo, São Paulo, 1988.
GARCÍA, C. M. La formación inicial y permanente de los educadores. In: Ministerio de Educación, Cultura y Deporte. Consejo Escolar del Estado. Los educadores en la sociedad del siglo XXI. Madrid: Universidad de Sevilla, 2002. p. 165-194.

GUSKEY, T. R. Evaluating professional development. Califórnia: Corwin Press, 2000. 308 p.

GUSKEY, T. R.; HUBERMAN, M. Professional development in education: new paradigms and practices. New York, USA: Teachers College Press, 1995.

MANCINI, M. C.; SAMPAIO, R. F. Quando o objeto de estudo é a literatura: estudos de revisão. Revista Brasileira de Fisioterapia, São Carlos, v. 10, n. 4, p. 361-472, out./dez. 2006. Disponível em: $<$ http://www.scielo.br/scielo.php?script=sci_arttext\&pid=S1413-35552006000400001\&lng=en\&nrm=iso $>$. Acesso em: 19 jun. 2015.

MOLINA NETO, V. A formação profissional em educação física e esportes. Revista Brasileira de Ciências do Esporte, Florianópolis, v. 19, n. 1, p. 34-41, 1997. Disponível em: <http://revista.cbce.org.br/index.php/RBCE/ issue/view/79>. Acesso em: 14 out. 2011.

MOREIRA. M. J. C. Projeto professor nota 10: um impacto na prática de formação continuada de professores no Distrito Federal. 2006. 116f. Dissertação (Mestrado em Educação) - Universidade Católica de Brasília, Brasília, 2006.

PACHECO, J. A.; FLORES, M. A. Formação e avaliação de professores. Porto, Portugal: Porto Editora, 1999. 193 p.

PAIM, M. C. C.; LORO, A. P.; TONETTO, G. A formação contínua dos professores de educação física escolar. Revista Digital, Buenos Aires, ano 13, n. 119, abr. 2008. Disponível em: <http://www.efdeportes.com/efd119/a-formacao-continua-dos-professores-de-educacao-fisica-escolar.htm/>. Acesso em: 24 maio 2011.

PORTO, Y. Formação continuada: a prática pedagógica recorrente. In: MARIN, A. J. (Org.). Educação continuada: reflexões, alternativas. Campinas: Papirus, 2000. 